\title{
NURSES LIVED EXPERIENCES OF CONSCIENCE REACTION: A QUALITATIVE PHENOMENOLOGICAL STUDY
}

\author{
Parkhideh Hasani $^{1}$ Rostam Jalali ${ }^{2}$ Zhila Abedsaeedi $^{3}$ \\ 1. Assistant Professor, PhD of Nursing, Shahid Beheshti University of Medical Sciences. \\ 2. MsN, PhD Student of Nursing. Shahid Beheshti University of Medical Sciences. Nursing \\ Department, Shahid Beheshti's Faculty of Nursing and Midwifery, Taqatoae Niayesh-Vali ASR, \\ Tehran-Iran. Ks jalali@yahoo.com Cell Phone +989181324821 (Corresponding Author)
}

3. Assistant Professor, PhD of Management in Health Services, Shahid Beheshti University of Medical sciences.

\begin{abstract}
Background and objectives: Conscience is a cornerstone of ethics, affecting both our private and professional lives. Everyday health care practice raises questions about conscience and how to understand its role. Conscience has also been described as inducing self-growth and protecting personal integrity. Nurses views on their reactions to behaviors consistent or contrary to conscience could therefore help us to understand the meaning of the reactions of conscience. This study aimed to illuminate meanings of nurses lived experience of conscience reaction in their daily practices.
\end{abstract}

Material and methods: Interviews with nine nurses were interpreted using a phenomenological hermeneutic (Colaizzi, 1978) method. Data was collected in 2010 among nurses working in various hospitals in Kermanshah. The nurses were selected for participation purposively.

Results: The nurses lived experience of conscience reaction was formulated in three themes and ten sub-themes. The first theme is 'being peace, which includes three sub-themes: Being calm, being pleased, and being satisfying. The second theme is 'trouble conscience' which includes four subthemes: guilt, thinking engagement, discomfort, and fretfulness. The third theme is responding which includes three sub-themes: expressing, compensation, and lack of repeat.

Conclusions: The nurses lived experience of conscience reaction showed that nurses considered conscience reaction to be an important factor in the exercise of their profession, as revealed by the descriptive categories: being peace when they act consistent with conscience; trouble conscience when they act contrary on conscience; and responding after doing an anti conscience practice. They perceived that conscience played a role in nursing actions involving patients and next of kin, and guided them in their efforts to provide high quality care.

Keywords: phenomenology, conscience reaction, nurses, lived experience.

Introduction and statement of the problem: Nurses are considered as the conscience of health care systems. Thus, they not only have positive effect on public health, but also play a key role in improvement of health care systems. They are responsible for fulfillment of the methods that enhance access to safe, high quality, and competent heath care (Sincox, 2005). Moreover, they are in charge of providing nursing care to all patients without any prejudice and judgment, in a direct and timely manner with high quality. Respecting people's rights and treating people with regard to their dignity is an inseparable part of heath care systems (Jansen and Lidell, 2009). In nursing, moral topics point to the values that govern the relationship of nurses and patients (Fawcett, 2005). To direct the relationship and moral acts, a sensitive conscience is needed; thus it is an important item for health care providers, and violating it without bringing about major adverse effects on moral integrity is not possible (Dahlqvist et al. 2009). Conscience is the foundation of morality and influences private and professional life (Dahlqvist et al. 2007). When nurses are taking care of critically ill patients, they remember the patients they did not sufficiently take care of. Sorlie quoting from Ricoure discusses 
morality memory. According to him, people never want or never can, and in fact should not, forget good or bad events in their life. Thus, nurses do not forget the patients whom they did not sufficiently look after (Sorlie et al. 2003). Conscience originates from the living experience and is a part of our daily and professional life and we cannot get rid of or escape from it (Kulka, 2002). When a nurse stands contrary to his/her interest, there are conflicts of value, that mean; the nurses prohibited to delivery care appropriately, or when they haven't choices and must participate in caring that is contrary to human dignity, and also may emerge when the nurses can't defend for his/her ideals (Post, 1998). Conscience conflict can lose the individual integrity. Nurses coercion to engaging in activities that is inconsistent with conscience, cause to desertion nursing profession. Although protecting of nursing conscience must be guarantee against professional coercion (Curtin, 1993). Otherwise cause troubled conscience and shame and guilt for not following conscience (Post, 1998). If we do not follow conscience, blaming and expostulation phenomenon seen clearly. Clearance and consistency of this phenomenon is more than other conscience phenomena. Absolutely blaming is the aspect of conscience that protects our ideal personality, and promotes it more ever is an antecedent for psychological development. This phenomenon is the greatest humanistic condition that human being has a clear conscience. These people benefits of all conscience activities (Jafari, 2009). Guiltiness and conscience permit us to promote our actions; now, past and in the next. In continuum we decide, which of the actions must be accepted or rejected. Inability in balancing can cause guilty in persons that they are susceptible to guiltiness. If we have guiltiness and blaming, then we left animal hostility and entering to humanity domain (Gaylin, 1994). In contrast, when a nurse practice accordance with his/her conscience, he/she hasn't anxiety, and with resolve the cause of anxiety and comprehension, the conscience become calm and find normal condition (Jafari, 2009). The morally sensitive and susceptible individuals have grief when they act against their conscience, but the others hadn't (May, 2001). Having conflict before or after doing an action and nurse's reaction to consistency with conscience practice must be investigated precisely. Nurse's experiences from their reactions to consistent and inconsistent behaviors can help us to understand meaning of conscience reaction.

In his working experience, the author has observed how nurses encounter conscionable issues during care providing, and due to different reasons they cannot act in accordance with their conscience. Thus, the current study was carried out with a qualitative approach, which is suitable for evaluation of individuals' experience, beliefs, and priorities. By understanding the experience of nurses, the study would be helpful to elucidate the nature of conscience's reaction in nursing.

Methodology: The current study was carried out to perceive the nurses' living experience of conscience with a phenomenological method. It is a study with a qualitative approach. Phenomenological research is a type of qualitative research with philosophical roots focused on the experience of man's life (Polit et al., 2005). Phenomenology is in fact an attempt to describe living experience without previous theories about their objective reality (Strubert and Carpenter, 2007). In phenomenology, the context of the event and the occurrence of the phenomenon are the interpretational factors in understanding the world of participants or the events and phenomena under evaluation. With the language of participants, the qualitative researcher associates the practical items and the living experience of the individual by rational involvement and entering the unique world of the participant of the study (Benner, 1994). The participants were chosen purposively and their number was determined by data saturation criterion, and the task was consequently repeated until the data saturated and the themes repeated (Strubert and Carpenter, 2007).

Characteristics of data gathering tools and method of data gathering: The main tool for data gathering was extensive, in-depth, unstructured, and interactive (face-to-face) interview. The interviews were recorded, transcribed at the earliest possible time, and then immediately encoded and analyzed. Moreover, the goal-oriented observation of phenomenon under study (observation of verbal and non-verbal behaviors) in the natural context and in appropriate time by the observer as a participant were performed, recorded, encoded, and then analyzed.

Inclusion criteria: The participants were selected from among the individuals who have direct experience of nursing conscience (the background of working as a nurse) and were willing to attend the study. The lowest educational level was B.Sc. of nursing. The participants did not have speaking or hearing problems. Furthermore, they were willing to narrate their perceptions (experience). The participants were informed and attended the program voluntarily. 
Sampling method: The participants were asked to attend the study by an invitation letter. After returning the invitation letter and accepting to participate the study, the time of interview was set by telephone or in person. Following the signing of an informed written consent, according to the schedule, the participants attended an unstructured interview at their working place or whenever they preferred. Face-to-face interview provides first hand information by discovering the real experience and brining the researcher to the context of the topic. Moreover, during the interview, the participant is given feedback, and thus verifying and additional data can be obtained. The interviews were recorded and then transcribed. Combination of in-depth interview and observation increase the validity of data and weakness of a data gathering method is covered by another method. Each interview took 20 to 60 minutes. If needed, the interview with a single participant carried out in several sessions. After performing each interview, the recorded interview was carefully listened several times. Then, word for word, the interviews transcribed with Microsoft Word Software and then printed. The procedure performed for all interviews. After transcription, the researcher reviewed the texts when listening the recorded interviews. This was carried out to enhance the preciseness of transcribed data and to increase the researcher's comprehension of the data. After carrying out these steps, the transcribed data was considered as the raw data to be analyzed.

General steps of data analysis: The data were analyzed according to the steps of Colaizzi's data analysis (1978). The method includes nine steps as follows:

1- Describing the interested phenomenon, 2- Gathering the participants' description of the phenomenon, 3- Reading all the participants' description of the phenomenon, 4- Return the original transcripts and extract significant statements, 5- Trying to spell out the meaning of each significant statements, 6- Organizing the aggregate formalized meaning into clusters of themes, 7- Write an exhaustive description, 8- Return to the participants for validation the description, and 9- If new data are revealed during the validation, incorporate them into an exhaustive description (Colaizzi, 1978). In the current study, we followed the stages of data analysis step by step. Moreover, for recording behaviors, non-verbal communications, appearance, facial expression, and eye contact of participants, we used observation and note taking during the unstructured interview with the unstructured observation method. To do so, the observations were recorded if possible during the interview, or immediately after that. The data was used in transcription of interview data and its analysis.

Trustworthiness of research data: Common methods of qualitative studies were used to verify the trustworthiness of the data. In the current study, the method suggested by Guba and Lincoln (1994) was used.

To verify the creditability of the data, we used a combination of data collection method (unstructured interview, field note taking, and memoing), revision by participants, and revision of codes and categories by professionals. To verify the reliability and dependability of the data, we used detailed description of the study. Thus, it can be evaluated by external observers. To justify the confirmability of the research, all steps of the study, including data collection and analysis and extraction of codes and categories were described such that other people could judge them by reading the descriptions. To check the transferability, the results were given to three nurses who did not attend the study and their experience was compared with the results of the current study.

Ethical considerations: After receiving the approval of observation of ethical issues from the Ethics Committee of Research Department of Shahid Beheshti Medical University, all participants signed an informed written consent and then we came to an agreement with the participant on the time and place of the interview. After describing the objectives of the study and the voluntary involvement in the study, the permission to record the interviews was taken.

Findings: In general, nine participants from among the nurses working in educational hospitals of Kermanshah attended in-depth interviews (Table 1). If there were any ambiguity in content analysis of the interview, we removed the ambiguity by re-visiting the participant or calling him/her. The interviews were carried out by the researcher (the first author). Encoding and extraction of main items was also done by the researcher and the main coworkers, and then the results were revised and modified by external observers and the participants. With continuous analysis of the data and analysis of the interview notes on the experience and beliefs of nurses about the reaction of conscience was 
formulated in three themes and ten sub-themes. The first theme is 'being peace, which includes three sub-themes: Being calm, being pleased, and being satisfying. The second theme is trouble conscience' which includes four sub-themes: guilt, thinking engagement, discomfort, and fretfulness. The third theme is reaction which includes three sub-themes: expressing, compensation, and lack of repeat (Table 2).

Table 1: Characteristics of the participants

\begin{tabular}{|c|c|}
\hline Educational level & BS 8 nurse, MS 1 nurse \\
\hline Sex & Female 6, Male 3 \\
\hline Age & Mean 32.5 Range 26-45 yrs \\
\hline Nursing experience & Mean 9.5 Range 2-22 yrs \\
\hline Interview duration & $20^{\prime}$ to 60 '; mean =35' \\
\hline Nursing role & Head nurse 1, Supervisor 1, clinical nurse 7 \\
\hline
\end{tabular}

Being Peace: One of the major concepts extracted from the data was the peace of conscience, which includes three sub-themes: Being calm, being pleased, and being satisfying. Most participants talked about being peace of conscience. However, they mentioned that being peace is as being calm, being pleased and being satisfying. In this regard, the nurses mentioned:

"Often occurred these things, I have a sense of calming, often occurred that I say, I do widget; I have calming sense, I sense today is a day that go on to my willingness..."

"... if I do some things accordance to my conscience; I'll very glad ..."

"In the time of acting accordance with conscience; I sense satisfying, that mean; I do correct action ..."

Trouble of Conscience: A pivotal concept extracted from the data and on the basis of experience of the participants was trouble of conscience. This concept consist four sub-themes: guilt, thinking engagement, discomfort, and fretfulness. Regarding this fact, nurses mentioned that:

"If I do some things against my conscience ... I think; I am not appropriate for this job and I have an internal sense of discomfort ..."

"... but I have a challenge with myself; I am engaging in my inward; there is more conscience engagement ..."

"If I do some things against my conscience; I am discomfort; because it is different from happiness. It cause more discomfort for me"

"If I do some things against my conscience; the first thing for me is a blaming condition and internal discomfort ..."

Reaction of Conscience: Of the main concepts extracted by the data analysis were reaction of conscience, which included three sub-themes; expressing, compensation, and lack of repeat. In this regard, the nurses considered that: 
"... Because I do a positive action; and ... I have a good sleep after it, fortunately or regret; I express always and very soon in my home; I say: I do a good action today ..."

"If I being the cause of this encounter; I try to compensate anyways; to convince them... but anyway I do to compensate it..."

"If I do some things against my conscience; I try to don't repeat in the next time... but I don't repeat this wrong action never ... I try to don't repeat in the next time forever".

Table 2: Major and minor categories of reaction of conscience

\begin{tabular}{|c|c|c|}
\hline Theme & Sub-theme & codes \\
\hline \multirow[t]{3}{*}{ Being Peace } & Being Calm & $" \ldots$ I have a sense of calming, $\ldots$ I have calming sense \\
\hline & Being Pleased & if I do some things accordance to my conscience; I'll very glad \\
\hline & Being Satisfying & $\begin{array}{l}\text { I have a complete satisfying with acting accordance to } \\
\text { conscience; I sense that lost my exhaustion. }\end{array}$ \\
\hline \multirow{4}{*}{$\begin{array}{l}\text { Trouble of } \\
\text { Conscience }\end{array}$} & guilt, thinking & Reaction to work against conscience! sense of guiltiness. \\
\hline & engagement & I have a challenge with myself; I am engaging in my inward \\
\hline & discomfort & $\begin{array}{l}\text { If I do some things against my conscience; It cause more } \\
\text { discomfort for me }\end{array}$ \\
\hline & fretfulness & The first thing is blaming; you ashamed yourself anyway \\
\hline \multirow{3}{*}{$\begin{array}{l}\text { Reaction of } \\
\text { Conscience }\end{array}$} & expressing & I express always and very soon; I say: I do a good action today \\
\hline & compensation & I compensate it as soon as possible \\
\hline & lack of repeat & I try to don't repeat in the next time \\
\hline
\end{tabular}

Discussion : The findings showed that reaction of conscience in nurses' experiments include three pivotal concept; the being peace, trouble conscience, and reaction of conscience. One of the findings was the being peace. Participants expressed their experience on acting accordance with conscience as calming, pleased and having satisfied. In this regard, Jafari wrote; the human conscience has capacity to accepting authenticity, and good practices followed by conscience satisfaction. Really, the conscience has a sense of satisfaction on justice and fairness. He says; our relative knowledge doesn't give us the peace that we expect it, but, only conscience can create the calming (Jafari, 2009). On the basis of the dictate of conscience, a person can perform an action that will provide the basis for the development of the relevant virtues (Stanford University, 2011). The calm conscience presents us certainty and calming. One of the amazing phenomenon in our inside is that, this certainty from the view of exploration is marked, but, when created by conscience; is the same as seeing it and still, higher than seeing, can sensed as the component of the our body(Jafari, 2009). Participant in this study, paid attention to calming, satisfying and pleased after following their conscience.

Another theme that emerged from analysis of data was trouble of conscience; because of threatening of moral integrity. Nurses have reported feeling of trouble conscience in situation in which they felt unable to provide the quality of care they believed their duty required for them. Nurses feel guilty and inadequate when they fall short of perceived performance standards (Sorlie et al., 2003). Troubled conscience has been described as a positive force that develops our moral values; it makes us aware of our values, even though its negative consequences are more frequently described. For nurses, an inability to act according to their conscience is associated with several phenomena: decreased wellbeing in nurses and patients, high turnover rates and shortage of nurses, burnout, and distancing from patients (Glasberg et al., 2006). Troubled conscience, such as feelings of guilt, is experienced by care providers, for instance, when not fulfilling their perceived obligations to patients. These obligations can be dictated either by oneself or by others, such as patients, management or the organization (Juthberg et al., 2007). Circumstances and demands may conflict with the care providers' moral values. Conscience can be understood as a person's integrated moral values and discrepancies between circumstances, demands and the care providers' moral values may trouble the care providers' conscience (Juthberg \& Sundin., 2010). Conscience relates to moral responsibility. Failing one's moral responsibility, whether related to personal failures or to situational constraints may 
lead to moral distress and stress of conscience (stress related to troubled conscience) which are both related to burnout. Stress of conscience is found to be associated with factors such as not being able to follow one's conscience and of being morally burdened (Glasberg et al., 2008). The nurses try to resolve these stress and burden simultaneously with having discomfort, guiltiness and blaming; by performing several actions such as compensating, don't repeating and expressing under the name of reaction of conscience theme. Consciences call the people to left wrongness and attend to rightness and establish a level of selfish and authenticity (Lederman, 2003). Conscience acts as; internal restrain and individual moral authority (Johnston, 2006). Conscience has also been described as inducing self-growth and protecting personal integrity. It can be consulted in care situations with the intention of protecting the integrity and dignity of all individuals involved (Dahlqvist et al., 2007). Guilt helps to shape the morality or character of a person, and anticipation of guilt prevents wrongdoing. Ricoeur points to the warning function of conscience and underlines its significance for being and acting ethically. In the dialectics between attestation and suspicion, coming from questioning what is good, we develop as moral beings (Glasberg et al., 2008). In health care, conscience perceived as a warning against doing wrong helps to protect the fundamental integrity, wholeness and harmony of persons involved in care. Nurses refer to their previous experiences of troubled conscience to help them make decisions in future situations and to teach them to use their conscience to make controversial decisions (Post, 1998).

Conclusion: The lived experience of nurse on reaction of conscience was specified in three categories; being peace, trouble of conscience, and reaction of conscience. Though the nurses in this study showed troubled conscience; when acting against their conscience and being peace; when acting consistent with conscience, but, they told; troubled conscience is a developing factor for conscience. Although the results were consistence with those of other studies, the emphasis of participants on different aspects of conscience was different from the findings of other studies; such that the item of the highest importance in another study did not have the same level of importance in the current study. Furthermore, the participants were nurses of different wards, while it seems that the nurses' perception of conscience in various wards or different hospitals can be different. Thus, besides providing some mechanisms to reinforce nursing conscience or removing the factors that impair the nursing conscience, it is suggested to carry out some more specific studies in specialized wards or hospitals.

\section{References:}

Benner P, (1994). Interpretive phenomenology: embodiment, caring, and ethics in health and illness. Thousand Oaks, Ca: Sage Publication; New York.

Colaizzi PE (1978). Psychological research as the phenomenologist views it. Existential phenomenological alternative for psychology. New York: Oxford University Press.

Curtin L.(1993). Conscience and clinical care. Nursing Management,; 24(8): 26-9.

Dahlqvist V, Eriksson S, Glasberg AN, Lindahl E, Lutzen K, Strandberg G, Soderberg A, Sorlie V, Norberg A (2007).Development of the perceptions of conscience questionnaire. Nursing Ethics; 14(2)181-193.

Dahlqvist V, Soderberg A, Norberg A, (2009).Facing inadequacy and being good enough: psychiatric care providers' narratives about experiencing and coping with troubled conscience. Journal of Psychiatric and Mental Health Nursing; 16, 242-24.

Fawcett J( 2005 )Analysis and Evaluation of Contemporary Nursing Knowledge :Nursing Models and Theories .Canada, F.A.Davis Co.

Gaylin W. Conscience: knowing good and doing good. The Hastings Center Report, 1994; 24(3): 36.

Glasberg AN, Eriksson S, Dahlqvist V, Lindahl E, Strandberg G, Soderberg A, Sorlie V, Norberg A (2006).Development and initial validation of the stress of conscience questionnaire. Nursing Ethics;13(6)633-648. 
Ann-Louise Glasberg AL, Eriksson S, Norberg A. (2008). Factors associated with 'stress of conscience' in healthcare. Scandinavian J of Caring Sciences; 22; 249-258.

Guba EG, Lincoln YS. (1994). Competing paradigms in qualitative research. Handbook of Qualitativr Research. Thousand Oakes, CA: Sage.Jafari M.T. (2009). Conscience, Fourth edition. Institute for the publication of Allameh Jafari's works, Tehran, (Persian).

Jensen A, Lidell E (2009).The influence of conscience in nursing. Nursing Ethics; 16(1)31-42.

Johnston M-J (2006). Bioethics: a nursing perspective. $4^{\text {th }}$ edition, Churchill Livingstone, London.

Juthberg C, Eriksson S, Norberg A, Sundin K (2007).Perception of conscience in relation to stress of conscience. Nursing Ethics; 14(3):329-343.

Juthberg C, Sundin K (2010). Registered nurses' and nurse assistants' lived experience of troubled conscience in their work in elderly care-a phenomenological hermeneutic study. International Journal of Nursing Studies; 47:20-29.

Kukla R. (2002). The ontology and temporality of conscience. Continental Philosophy Review; 35: 134.

Lederman E. (2003). Conscience And Bodily Awareness: Disagreements With MerleauPonty. Journal of the British Society for Phenomenology; 13(3): 286-295.

May T. (2001). Rights of Conscience in Health Care. Social theory \& Practice. 27(1): 111-118.

Polit D.F, Beck C.T, Hungler B.P (2005) Essentials of Nursing Research :Methods, Appraisal, and Utilization $.5^{\text {th }}$ Edition .USA, Lippincott Co.

Post, I. (1998). Perioperative nurses' encounter with value conflicts: a descriptive study. Scandinavian Journal of Caring Sciences, 12 (2): 81-88.

Sincox K (2005) The conscience of the health care system. Michigan Nurse, August: available at: www.minurses.org.

-Sorlie V, Jansson L,Norberg A (2003). The meaning of being in ethically difficult care situations in paediatric care as narrated by female Registered Nurse. Scandinavian Journal of Caring Sciences; $17: 285-292$. .

-Streubert H, Carpenter DR (2007). Qualitative Research in Nursing., $4^{\text {th }}$ edition Lippincott William and Wilkins, Philadelphia.

www.plato.stanford.edu/enteries/conscience-medieval/ 